\title{
Nilai Moral dan Religius pada Novel Maysuri Karya Nadjib Kartapati Z.
}

\author{
Sri Mulyani \\ Universitas Indraprasta PGRI \\ Jalan Nangka No. 58 C/TB. Simatupang, Tanjung Barat, Jakarta Selatan 12530
}

\begin{abstract}
The research aims to analyze the moral and religious values of the novel Maysuri by Nadjib Kartapati Z. The results show of one hundred two (102) quotations of moral values and sixty four (64) with the following details: (1) Moral values in the Maysuri novel Nadjib Kartapati Z. turned out to be dominated by the first aspect of human relations with others, amounting to $69.6 \%$, meaning that there are high values of relationships between people as manifestations of social beings. Both aspects of human relations with him by $20.6 \%$, meaning that there is selfishness in humans. The third aspect of humans with nature is 5.9\%, meaning that the value of caring for nature is lacking. The four aspects of human relations with society amounted to 3.9\%, meaning that this aspect was ranked last, in fact human relations with the community were very low. (2) While the religious value in the novel Maysuri by Nadjib Kartapati Z. The first turned out to be dominated by the moral aspect that is equal to 50\%, meaning that morality becomes the main foundation of humans in living life. Both aspects of shari'ah with $25 \%$, meaning that observance in worship is still largely abandoned. The three aspects of the creed are the same as the shari'ah aspect with 25\%, meaning that belief in religious values is relatively low.
\end{abstract}

Keywords: moral values, religious values, Maysuri novels.

\begin{abstract}
Abstrak
Penelitian bertujuan untuk menganalisis nilai moral dan religius pada novel Maysuri karya Nadjib Kartapati Z. Hasil penelitian menunjukkan dari seratus dua (102) kutipan nilai moral dan enam puluh empat (64) dengan rincian sebagai berikut: (1) Nilai moral pada novel Maysuri karya Nadjib Kartapati Z. ternyata didominasi pertama aspek hubungan manusia dengan orang lain yaitu sebesar $69,6 \%$, artinya ada nilai-nilai hubungan yang tinggi antarmanusia sebagai manifestasi makhluk sosial. Kedua aspek hubungan manusia dengan dirinya sebesar $20,6 \%$, artinya ada keegoan dalam diri manusia. Ketiga aspek manusia dengan alam sebesar 5,9\%, artinya nilai kepedulian terhadap alam sangat kurang. Keempat aspek hubungan manusia dengan masyarakat sebesar 3,9\%, artinya aspek ini menduduki peringkat paling akhir, ternyata hubungan manusia dengan masyarakat sangat rendah. (2) Sementara nilai religius pada novel Maysuri karya Nadjib Kartapati Z. tersebut ternyata pertama didominasi oleh aspek akhlak yaitu sebesar 50\%, artinya akhlak menjadi pondasi utama manusia dalam menjalani kehidupan. Kedua aspek syari'ah dengan $25 \%$, artinya ketaatan dalam beribadah masih banyak ditinggalkan. Ketiga aspek akidah sama dengan aspek syari'ah dengan $25 \%$, artinya kepercayaan terhadap nilia-nilai religius relatif rendah.
\end{abstract}

Kata Kunci: nilai moral, nilai religious, novel Maysuri

\section{PENDAHULUAN}

Perkembangan globalisasi era milenial memberikan banyak dampak terhadap masyarakat bangsa ini. Salah satu yang terkena imbas dari perkembangan era ini yaitu adanya degradasi moral. Hal ini bisa dilihat dari banyaknya kasus yang 
melibatkan menurunnya akhlak terpuji seseorang. Hampir setiap hari media masa maupun elektronik memberitakan tentang kekerasan atau konflik horizontal antarwarga yang dipicu oleh masalah-masalah sepele.

Akhir-akhir ini banyak sekali kasus yang memprihatinkan terkait dengan merosotnya moral masyarakat negeri ini. Salah satu kasus terbaru yaitu banyaknya pejabat-pejabat pemerintahan yang tersandung kasus korupsi. Sebut saja kasus penyuapan terhadap proyek Meikarta di Kabupaten Bekasi. OTT-nya Bupati Cirebon oleh KPK, Kasus megakorupsi E-KTP dan lain -lain. Kasus-kasus seperti ini sangat memperlihatkan bagaimana semakin rendahnya nilai-nilai kejujuran dalam kehidupan yang semakin modern. Bagaiman nilai kejujuran tidak lagi menjadi prioritas untuk membangun diri agar dipercaya oleh orang lain.

Belum lagi kasus kekerasan yang terjadi menimpa anak-anak dan remaja. Data dari KPAI per tanggal 30 Mei tahun 2018, kasus anak korban tawuran sebanyak 23 (14,3 persen), anak pelaku tawuran sebanyak 31 (19,3 persen), anak korban kekerasan dan bulying sebanyak 36 (22,4 persen) dan anak pelaku kekerasan bulying sebanyak 41 (25,5 persen) (IDN Times, 2018). Angka-angka tersebut menunjukkan betapa banyaknya kasus kekerasan akibat rendahnya moral dan keimanan seseorang. Akhlak tidak lagi menjadi pijakan logis ketika bertindak sehingga banyak perbuatan yang melanggar baik norma sosial maupun norma hukum.

Kasus yang paling menyedihkan terjadi pada (30/09/2018) di Sunter, Jakarta, 23 pria digrebek polisi karena tengah pesta sabu-sabu dan diduga melakukan hubungan sejenis (Tribunjogja, 2018). Ditambah lagi kasus pelecehan seksual terhadap anak kecil yang sangat memilukan, betapa hilangnya daya nalar kelogisan ketika akan bertindak. Dahulu kasus-kasus seperti ini hanya terjadi di luar negeri, namun sekarang merebak di dalm negeri.

Menurut Eibel merosotnya nilai moral masyarakat bangsa ini dipengaruhi oleh faktor kemajuan teknologi, memudarnya kualitas keimanan, dan pengaruh lingkungan. Faktor-faktor itulah yang mempengaruhi semakin memudarnya nilainilai kejujuran, rasa sosial dan tanggung jawab. Tentu hal ini merupakan bentuk keprihatinan yang luar biasa yang perlu dicarikan solusi yang tepat. Semua pihak harus benar-benar terlibat dalam membenahi moral yang sudah terkontaminasi oleh arus globalisasi yang kekinian tanpa dibarengi dengan keimanan yang kuat.

Merosotnya nilai moral tentu dilandasi oleh merosotnya kadar keimanan atau nilai-nilai religius seseorang. Hal ini karena nilai religius didasari oleh nilainilai agama yang memuat nilai haram dan halal, baik tidak baik dan pantas tidak pantas. Nilai religius akan menjadi pondasi kuat tindakan seseorang. Jika nilai religius kuat tidak ada lagi kemerosotan nilai-nilai moral. Nilai religius membangun kekuatan diri untuk menghindari kegiatan-kegiatan yang dianggap melebar dari norma-norma asusila. Oleh karena itu, masyarakat Indonesia harus mampu menjaga dan mengembangkan bahkan meningkatkan nilai-nilai religius demi terciptanya kondisi yang baik dalam kehidupan.

Begitu pentingnya nilai moral dan religius harus menjadi pedoman masyarakat bangsa ini agar tidak terpuruk. Nilai moral dan religius yang terkandung dalam sikap dan perilaku hidup berbangsa dan bernegara seharusnya menjadi perekat dalam menjalani kehidupan di tengah heterogenitas masyarakat negeri ini.

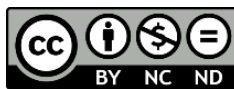

Creative Commons Attribution-NonCommercial-NoDerivatives 4.0 International License 
Bangsa Indonesia yang kaya akan suku, budaya, agama dan ras seharusnya menjadi cikal bakal bangsa yang menghormati perbedaan. Hanya saja permasalahannya terletak bagaimana belum siapnya transisi masyarakat negeri ini dengan kemajuan globalisasi terutama dampak negatif yang ditimbulkannya.

Fenomena nilai moral dan religius dalam masyarakat negeri ini bisa menjadi cerminan bagaimana perlu adanya media atau sarana yang bisa menjadi alternatif mengurangi dampak seperti kasus-kasus di atas. Salah satu yang bisa ditawarkan yaitu media dakwah berupa tulisan yang bisa membangkitkan kembali nilai-nilai kemanusiaan. Tulisan-tulisan yang bernilai dan bermutu baik bisa mengajak dan menuntun pembaca ke arah positif. Tulisan yang mampu menggetarkan kembali hati nurani manusia dari sifat khilaf.

Terkait dengan tulisan yang bermanfaat, salah satu tulisan yang bisa menambah wawasan mengenai cerita kehidupan yaitu karya sastra berbentuk prosa. Pesan-pesan dalam prosa bisa menjadi inspirasi pembacanya untuk berbuat sesuai dengan yang disampaikan penulis. Sastra mempunyai fungsi didaktif, moralitas, reaktif, estetis dan religius. Menurut Esten, Sastra adalah pengungkapan artistik dan imajinatif sebagai manifestasi kehidupan manusia dan masyarakat memalui bahasa sebagai medium dan memilki efek yang positif terhadap kehidupan manusia (kemanusiaan). Sementara itu, menurut Wellek dan Warren (2014: 3) sastra adalah suatu kegiatan kreatif, sebuah karya seni.

Sementara itu, Supinah dan Suhendar mengatakan sastra adalah hasil kehidupan jiwa yang menjelma dalam tulisan atau bahasa tulis yang menggambarkan atau mencerminkan peristiwa kehidupan masyarakat atau anggota-anggota masyarakat itu (1993:2). Pendapat tersebut mengemukakan bahwa sastra adalah hasil rekaman kehidupan manusia yang didokumentasikan dengan tulisan. Cerminan-cerminan kehidupan sehari-hari direkam melalui tulisan sehingga akan menjadi pengalaman tersendiri bagi yang membacanya. Sastra yang penuh dengan dilematika problem kehidupan baik dari hasil pengalaman maupun rekaan akan membuat pembacanya merasakan kesan tersendiri apalagi kalau dibalut dengan konflik dan diksi yang bagus.

Bentuk dari karya sastra yang banyak di baca yaitu novel. Novel adalah cerita yang berbentuk prosa dalam ukuran yang luas, yang menguraikan peristiwa kehidupan seseorang yang luar biasa, dan berakhir dengan perubahan nasib kehidupan pelakunya (Supinah dan Suhendar, 1993: 154). Sedangkan menurut Sumarjo Novel adalah bentuk sastra yang paling popular di dunia. Bentuk sastra ini paling banyak dicetak dan paling banyak beredar, lantaran daya komunitasnya yang luas pada masyarakat. novel memang memilki daya tarik bagi pembacanya karena banyak mengandung nilai-nilai di dalamnya.

Novel memiliki nilai-nilai yang patut untuk diteladani dalam kehidupan sehari-hari. Biasanya penulis novel menyisipkan pesan di dalamnya. Pesan-pesan yang terkandung memang tidak escara eksplisit ditampilkan. Namun, melalui pembacaan dan pemahaman yang tepat, pembaca akan menemukan nilai-nilai didaktis di dalamnya. Ada pun nilai-nilai yang dapat diambil dari novel yaitu berupa nilai pendidikan, moral, religius, sosial, estetika, budaya dan politik.

Dari sekian banyak nilai yang ada dalam novel, nilai-nilai novel yang patut diteladani di antaranya nilai moral dan nilai religius. Menurut 
Mangunwijaya sastra sering memuat nilai-nilai religiusitas. Hal demikian terjadi karena pada awalnya semua sastra adalah religius (1988:11). Artinya, semula sastra lahir untuk acara-acara kebaktian manusia kepada Tuhan, sehingga sastra hadir bersamaan dengan upacara keagamaan tertentu. Melalui sastra manusia ingin mendekat dan menyatu dengan Tuhan lewat seni.

Sementara itu, menurut Darajat (dalam Kamaruddin, 1985: 9) moral adalah kelakuan yang sesuai ukuran (nilai-nilai) masyarakat yang timbul dari hati dan bukan paksaan dari luar, yang disertai pula oleh rasa tanggung jawab atas kelakuan (tindakan) tersebut. Tindakan ini haruslah mendahulukan kepentingan umum daripada kepentingan pribadi. Dalam Kamus Besar Bahasa Indonesia bahwa moral merupakan ajaran tentang baik buruk perbuatan dan kelakuan mengenai akhlak, budi pekerti, kewajiban, dan sebagainya (Suharso dan Ana Retnoningsih, 2009: 327).

Diangkatnya aspek religius dalam novel agar pembaca dapat mengambil hikmah terutama ketika membaca novel yang banyak mengandung nilai religinya. Novel yang mengandung religi akan menuntun pembacanya secara batiniah mendekatkan diri dengan Sang Pencipta melalui kegiatan-kegiatan keagamaan. Pembaca akan lebih merasakan imaji-imaji terhadap pesan keagamaan yang terkandung di dalamnya. Selain itu, kadang-kadang ada juga pembaca yang 'hijrah' secara batiniah setelah membaca novel tersebut.

Selain nilai religius, diangkatnya aspek nilai moral dalam novel dapat menjadikan jembatan penikmat sastra untuk lebih memahami arti sebuah baikburuk, pantas tidak pantas dan akhlak terpuji dari gambaran tokoh yang terlibat di dalamnya. Penyajian karakter tokoh yang mengandung nilai moral dapat menyajikan cerita yang menarik. Nilai-nilai moral inilah yang akan menentukan gambaran bagi penikmat sastra dalam menentukan sebuah kualitas sastra. Apakah sastra tersebut benar-benar menjadi wahana penyebar kebaikan atau tidak.

Dari sekian banyak novel, penulis mencoba meneliti novel Maysuri Nadjib Kartapati Z. Novel ini banyak memuat nilai-nilai religius dan moral yang dilukiskan melalui tokoh di dalamnya. Selain itu, banyak amanat lain yang sengaja penulis selipkan agar pembaca benar-benar tertarik dengan cerita yang terdapat dalam novel ini.

Novel Maysuri Nadjib Kartapati Z. dicetak oleh penerbit PT Pustaka Alvabet dan diterbitkan tanggal 1 Maret 2016 dengan tebal 305 halaman. Novel yang bertemakan gadis seorang anak pelacur kemudian dibesarkan oleh seorang ayah yang mengerti agama sehingga menjadi gadis yang pintar dan cerdas terutama dalam hal keagamaan. Seorang gadis yang bernama Maysuri ini mampu mengangkat lembah hitam kehidupan ibunya yang tadinya seorang pelacur kemudian menjadi penganut agama yang taat atau hijrah di usia senja. Bahkan percintaannya dengan Buroqi harus terhalang gara-gara martabat ibunya. Pengarang dengan begitu apik menyajikan nilai-nilai moral dan religius dibumbui dengan percintaan yang sarat nuansa religiusnya.

Pengarang novel Maysuri ini adalah Nadjib Kartapati Z., seorang sastrawan dan penulis skenario film. Pria kelahiran Pati ini memperoleh berbagai penghargaan diantaranya penulis skenario FTV Terpuji dalam Festival Film Bandung tahun 2015. Kepiawaiannya dalam menciptakan karakter tokoh Maysuri menuai banyak 
pujian. Salah satu pujian terlontar pada halaman belakang buku dari Prof. Dr. Setya Yuwana Sudika, MA., mengatakan Nadjib Kartapati adalah sastrawan realis sekaligus penulis serba bisa. Ia piawai mempermainkan perasaan, sehingga tak jarang pembaca menitikkan air mata. Ending-nya seringkali mengejutkan, dan dalam membuat plot pun ia begitu kuat sehingga menghanyutkan emosi pembaca.

Dari 38 bab dalam novel Maysuri karya Nadjib Kartapati Z. ini, ada penggalan cerita yang menarik perhatian penulis seperti pada kutipan berikut.

"Entah jam berapa aku terlena. Namun aku merasa cuma sekejap. Aku tersadar lagi. Dan kulihat sajadah, di sisi kamar dekat dinding, ibu yang tubuhnya terbungkus rukuh dan mukena itu menadahkan tangan ke atas sambil berurai air mata. Ibu salat Tahajud? Subhanallah jam tembok menunjukkan pukul 02.35. inilah waktu emas untuk menangis di pangkuan Allah!"

Sesuai dengan penyataan di atas, penulis tertarik untuk meneliti nilai-nilai religi dan moral novel Maysuri karya Nadjib Kartapati Z. karena dalam novel ini menampilkan masalah dan realita yang memiliki relevansi dalam kehidupan seharihari. Dalam novel ini juga terdapat konflik-konflik sosial, moral, religius, politik, dan pergulatan batin Maysuri yang harus rela meninggalkan rumah demi ingin mengangkat harkat derajat ibunda tercinta dari jalan kesesatan. Relevansi pesanpesan yang tersemat dalam novel ini diharapkan dapat diaplikasikan dalam kehidupan nyata serta menjadi panutan norma bagi penikmat sastra baik di dunia pendidikan maupun masyarakat. Selain itu, penelitian ini dimaksudkan untuk membantu para apresiator dalam pemahamannya terhadap seni sastra yang semakin berkembang.

\section{METODE}

Menurut Sugiyono (2000:14), data penelitian dapat dikelompokkan menjadi dua yaitu data kualitatif dan data kuantitatif. Data kualitatif adalah data yang berbentuk kalimat, kata atau gambar. Sedangkan data kuantitatif adalah data yang berbentuk angka, atau data kualitatif yang diangkakan (skoring).

Sementara penelitian kualitatif dengan ciri deskriptif menurut Burhan (2007:185) dan menurut Vredenburght dalam Nyoman Kutha (2007: 66). Suawardi Endraswara (2005:5) membuat definisi bahwa, "penelitian kualitatif adalah penelitian yang dilakukan dengan tidak menyertakan angka-angka, tetapi mengutarakan kedalaman penghayatan terhadap interaksi antara konsep yang sedang dikerjakan secara empiris".

Berdasarkan teori tersebut, maka penelitian ini menggunakan pendekatan atau metode kualitatif, karena penelitian kualitatif adalah penelitian yang sesuai dengan fenomena sastra. Hal ini perlu dipahami sebab karya sastra adalah desain kata dan simbol yang penuh makna sehingga perlu diinterpretasikan maknanya agar mudah dimengerti, dan dipahami.

Analisis isi sebagai teknik analisis digunakan dalam pencarian fakta dengan interpretasi data suatu karangan, maksudnya dalam penelitian terhadap karangan, peneliti membaca karangan yaitu novel Maysuri karya Nadjib Kartapati Z., yang diperjelas, diklasifikasikan sesuai nilai moral tokoh utama dan nilai religius, serta frekuensi pemunculannya.

Prosedur penelitian yang dikemukakan oleh Vredenbreght tentang analisis isi dapat dilakukan dengan dua cara yaitu:

1) Analisis isi laten, isi yang terkandung dalam dokumen dan naskah. 
2) Analisis komunikasi, adalah analisis yang terkandung sebagai akibat komunikasi yang terjadi antara naskah dengan dokumen.

Teknik analisis dapat digunakan untuk wacana yang berhubungan dengan isi wacana novel, baik secara verbal maupun nonverbal. Wacana verbal berkaitan dengan keseluruhan isi yang ada dalam novel tersebut yang dijadikan objek penelitian.

Penelitian dilakukan dengan menggunakan instrument berbentuk tabel analisis. Table tersebut ialah table mengenai nilai moral dan nilai religius yang dikemukakan oleh Partiwintoro dkk.

\section{HASIL DAN PEMBAHASAN}

Sebagaimana telah disampaikan di atas bahwa penelitian ini berupa penelitian dengan data kualitatif yang terkait dengan objek penelitian novel Maysuri karya Nadjib Kartapati Z. Dalam deskripsi informasi penelitian ini akan dijabarkan berbagai penggalan cerita yang terkait dengan nilai moral dan religius dalam pada tokoh dalam novel tersebut.

Dan dari penelitian yang dilakukan menghasilkan temuan kutipan sebagai berikut:

\section{Kutipan Nilai Moral}

1. Kutipan nilai moral terhadap diri sendiri.

Bab I Tersungkur di Depan Rumah, Paragraf ke-6 :

"Itu artinya, Pak Pras menjadi orang yang kubutuhkan, dan oleh sebab itu sebisa mungkin aku tidak mengecwakannya." (Maysuri:2)

Berdasarkan kutipan di atas dapat dideskripsikan bahwa terdapat nilai moral terhadap diri sendiri. Maysuri menyadari bahwa dirinya tidak boleh mengecewakan siapa pun.

Bab I Tersungkur di Depan Rumah, Paragraf ke-13:

"Bagiku, restu dan kelegaan hati orangtua menduduki tempat yang terpenting, karena terbukti perjodohan tanpa restu orang tua, dari pihak mana pun, akan mengundang berbagai masalah yang pelik dan rumit." (Maysuri: 4)

Berdasarkan kutipan di atas dapat dideskripsikan bahwa terdapat nilai moral terhadap diri sendiri karena Maysuri menyadari bahwa restu orang tua adalah segalanya, tanpa doa dan restu orang tua hidup tidak akan bahagia.

2. Kutipan nilai moral terhadap orang lain

Bab I Tersungkur di Depan Rumah, Paragraf ke-11:

"Biarpun naik taksi, ada jalan kakinya 'kan?" lanjut Bunda. Kamu belum kuat, sayang. Lihat tuh muka kamu masih pucat" (Maysuri: 3).

Berdasarkan kutipan di atas dapat dideskripsikan bahwa terdapat nilai moral terhadap orang lain karena menasihati orang lain untuk tidak bepergian disaat kondisi badan masih sakit.

Bab I Tersungkur di Depan Rumah, Paragraf ke-19:

"Kalau May sudah enggak kuat jalan, orang pertama yang May maintain ngantor bukan Buroqi tetapi ayah!" (Maysuri: 4)

3. Kutipan nilai moral terhadap masyarakat

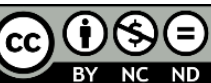


Bab XXVIII Konsultan Serba Masalah, Paragraf ke-15:

"Terdorong sikap perjuangannya, Soraya mempelopori gagasan kawin missal untuk para tunawisma tersebut." (Maysuri: 236).

Berdasarkan kutipan di atas dapat dideskripsikan bahwa terdapat nilai moral terhadap masyarakat karena keinginan kuat untuk memberikan kebaikan kepada masyakat yang belum mengerti agama terutama masalah pernikahan.

Bab XXVIII Konsultan Serba Masalah, Paragraf ke-16:

"Ada sebelas pasang tunawisma yang berhasil dinikahkan secara masal." (Maysuri: 236).

Berdasarkan kutipan di atas dapat dideskripsikan bahwa terdapat nilai moral terhadap masyarakat karena berupaya memberikan solusi dengan cara menikahkan massal masyarakat yang tidak mampu secara hukum agama.

4. Kutipan nilai moral terhadap alam

Bab XVI Padepokan Pak Sam, Paragraf ke-9:

"Pada bagian di luar bangunan-bangunan itu, tumbuh pohon-pohon rindang yang dibawahnya ditaruh bangku untuk duduk santai dipinggir bangunan ditanami berbagai tanaman hias sehingga bunganya pun mekar di sana-sini. Semua tertata demikian harmonis, dan kuyakini semua ini membutuhkan perawatan rutin setiap hari." (Maysuri: 141).

Berdasarkan kutipan di atas dapat dideskripsikan bahwa terdapat nilai moral terhadap alam karena berusaha untuk menjaga kelestarian lingkungan dengan merawatnya dan memeliharanya dengan baik.

Bab XVI Padepokan Pak Sam, Paragraf ke-29:

"Kerapian dan kebersihan yang selalu terjaga di koplek ini merupakan buah dari kebiasaan Pak Sam yang dilandasi oleh prinsip kemanusiaan." (Maysuri: 146).

Berdasarkan kutipan di atas dapat dideskripsikan bahwa terdapat nilai moral terhadap alam karena berusaha untuk menjaga dan melestarikan lingkungan yang bersih agar terhidar dari berbagai penyakit.

\section{Kutipan Nilai Religius}

1. Kutipan nilai aqidah

Bab I Tersungkur di Depan Rumah, Paragraf ke-2 :

"Kupusatkan konsentrasiku pada Sang Pemilik Daya dan Kekuatan agar menjaga kesehatanku yang terbilang baru saja pulih dari sakit kelelahan beberapa hari terakhir ini." (Maysuri:2)

Berdasarkan kutipan di atas dapat dideskripsikan bahwa terdapat nilai aqidah yaitu keyakinan terhadap Allah yang menciptakan manusia dengan segala kesempurnaannya agar menjaga kesehatan makhluknya.

Bab V Berita dari Rumah Sakit, Paragraf ke-10: 
"Pada saat aku pasrah, tak berharap apa pun mengenai lelaki yang akan mendampingi hidupku menyerahkan sepenuhnya kepada Allah akan jadi apa aku nanti, terjadi satu hal yang kemudian berbuntut panjang." (Maysuri: 30)

Berdasarkan kutipan di atas dapat dideskripsikan bahwa terdapat nilai aqidah yaitu Kepercayaan kepada Allah sebagai segala maha penentu dari setiap takdir manusia.

2. Kutipan nilai syari'ah

Bab X Mengenal Pak Sam Paragraf ke-21:

"Dan buktinya, tadi kita lihat sendiri kan? Badil datang dan khusyuk mengikuti pegajian kita." (Maysuri: 80)

Berdasarkan kutipan di atas dapat dideskripsikan bahwa terdapat nilai syari'ah mengikuti pengajian adalah bagian dari ibadah.

Bab XII Seruan Putus Cinta, Paragraf ke-9:

"Sebelum pamitan aku numpang shalat Ashar di rumah gedongan ini." (Maysuri: 102). Berdasarkan kutipan di atas dapat dideskripsikan bahwa terdapat nilai syari'ah karena shalat adalah bagian dari ibadah sebagai kewajiban setiap umat Islam.

3. Kutipan nilai Akhlak

Bab XII Seruan Putus Cinta, Paragraf ke-13:

"Maysuri! Assalamu'alaikum! Om senang kalau kamu mau datang ke rumah. (Maysuri: 102).

Berdasarkan kutipan di atas dapat dideskripsikan bahwa terdapat nilai aqidah karena mengucapkan salam bagian dari akhlak orang yang beriman.

Bab XVI Padepokan Pak Sam, Paragraf ke-10:

"Dari mushola muncul dua pemuda seusiaku. Mereka tersenyum ramah kepadaku seolah-olah aku ini teman yang sudah lama mereka kenal. (Maysuri: 141).

Berdasarkan kutipan di atas dapat dideskripsikan bahwa terdapat nilai aqidah karena menggambarkan sikap pemuda yang ramah dan memilki prinsip sopan-santun.

\section{SIMPULAN}

\section{Nilai Moral}

Berdasarkan hasil penelitian, nilai moral pada novel Maysuri karya Nadjib Kartapati Z. dapat diuraikan sebagai berikut. Aspek hubungan manusia dengan orang lain menduduki peringkat pertama, jumlahnya paling besar artinya ada nilai-nilai hubungan yang tinggi antarmanusia sebagai manifestasi makhluk sosial. Aspek hubungan manusia dengan dirinya menduduki peringkat kedua artinya ada keegoan dalam diri manusia itu sendiri. Aspek manusia dengan alam menduduki peringkat ketiga artinya nilai kepedulian terhadap alam sangat kurang. Aspek hubungan manusia dengan masyarakat menduduki peringkat terakhir artinya hubungan manusia dengan masyarakat sangat rendah.

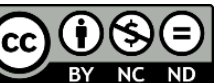


2. Nilai Religius

Nilai religius pada novel Maysuri karya Nadjib Kartapati Z. dapat diuraikan sebagai berikut. Pertama, aspek akhlak paling mendominasi artinya akhlak menjadi pondasi utama manusia dalam menjalani kehidupan sebagai kontrol diri agar melahirkan sifat terpuji. Kedua, aspek syari'ah dan aqidah nilainya sama artinya nilai ibadah dan kepercayaan terhadap nilia-nilai religius masih relatif rendah.

\section{DAFTAR PUSTAKA}

Aminuddin. (2004). Pengantar apresiasi karya sastra. Bandung: Sinar Baru Algensindo.

Arikunto, S. (2002). Prosedur penelitian. Jakarta: Rineka Cipta.

Daud, A. M. (2011). Pendidikan agama islam. Jakarta: PT. Rajagrafindo Persada.

Depdiknas. (2008). Kamus besar bahasa indonesia pusat bahasa (Edisi Keempat). Jakarta: PT. Gramedia Pustaka Utama.

Endraswara, S. (2011). Metode pembelajaran drama; apresiasi, ekspresi, dan pengkajian. Yogyakarta: CAPS.

Endraswara, S. (2008). Metodologi penelitian sastra; epistemologi, model, teori, dan aplikasi (Edisi Revisi). Yogyakarta: MedPress.

Frondizi, R. (2001). Pengantar filsafat nilai. Yogyakarta: Pustaka Pelajar.

Jauhari, H. (2010). Cara memahami nilai reilgius dalam karya sastra. Bandung: CV Arvino Raya.

Kaelan. (2008). Pendidikan pancasila. Yogyakarta: Paradigma.

Kartapati, N. (2016). Maysuri.Tanggerang Selatan: PT Pustaka Alvabet.

Koentjaraningrat. (2009). Pengantar ilmu antropologi (edisi revisi). Jakarta: Rineka Cipta.

Kosasih, E. (2012). Dasar-dasar keterampilan bersastra. Bandung: Yrama Widya.

Kurniati, N. (2013). Tesis: nilai-nilai pendidikan dan budaya dalam novel dunia kecil karya Yoyon Indra Joni. Palembang: Universita PGRI Palembang.

Luxemburg, J. V. (1991). Tentang sastra. (Diterjemahkan oleh Ikram). Jakarta: Intermasa.

Mangunwijaya, Y. B. 1988. Sastra dan religiositas. Yogyakarta: Kanisius.

Mulyana, Rohmat. (2004). Mengartikulasian Pendidikan Nilai.Bandung: Alfabeta.

Nurgiantoro, B. (2000). Teori pengkajian fiksi. Yogyakarta: Gajah Mada University Press.

Partiwintoro. (2002). Pengkajian nilai-nilai luhur budaya spiritual bangsa. Jawa Timur: Depdiknas

Ratna, N. K. (2008). Teori, metode, dan teknik penelitian sastra. Yogyakarta: Pustaka Pelajar.

Rachels, J. (2003). Filsafat moral (diterjemahkan oleh A. Sudiarja). Yogyakarta: Penerbit Kanisius.

Semi, M. A. (1993). Metode penelitian sastra. Bandung: Angkasa.

Siswanto, W. (2008). Pengantar teori sastra. Jakarta: Grasindo.

Sugiyono. (2006). Metode penelitian pendidikan. Bandung: Alfabeta. 
Sugono, D. (2014). Peran dan kekuatan bahasa indonesia dalam industri kreatif kebahasaan. Jakarta: Badan Pengembangan dan Pembinaan Bahasa Kementrian Pendidikan dan Kebudayaan.

Sumardjo, J. (2008). Ikhtisar sejarah teater barat (edisi revisi). Bandung: Angkasa.

Supinah, S. Suhendar, M.E. (1993). Pendekatan teori sejarah dan apresiasi sastra Indonesia. Bandung: Pionir Jaya.

Suparman. (2017). Tesis: nilai-nilai moral dan religius pada novel di anatara dua sujud karya Muhammada Irrata.Jakarta: Universitas Indraprasta PGRI Jakarta.

Tarigan, H. G. (2011). Prinsip-prinsip dasar sastra (edisi revisi). Bandung: Angkasa.

Teeuw, A. (2003). Sastera dan ilmu satera (edisi revisi). Jakarta: PT. Dunia Pustaka Jaya.

Waluyo, H. J. (2001). Teori drama dan pengajaran. Yogyakarta: Hanindita.

Wellek, R. \& Warren, A. (2014). Teori kesusasteraan. Jakarta: PT Gramedia 